\title{
Anti-islet autoantibodies detected by monoclonal antibody 1A2: further studies suggesting a role in the pathogenesis of IDDM
}

\author{
R.C. McEvoy ${ }^{1,2}$, N. M. Thomas ${ }^{1,2}$, F. Greig ${ }^{2}$, S. Larson ${ }^{2}$, I. Vargas-Rodriguez ${ }^{2}$, I. Felix ${ }^{1}$, E. Wallach ${ }^{2}$, P. Rubinstein ${ }^{3}$, \\ F. C. Goetz ${ }^{4}$, F. Ginsberg-Fellner ${ }^{2}$ \\ ${ }^{1}$ Department of Endocrinology, Children's Hospital and Medical Center, Seattle, Washington, USA \\ ${ }^{2}$ Department of Pediatrics, Mount Sinai School of Medicine, New York, New York, USA \\ ${ }^{3}$ Lindsley F. Kimball Research Institute, New York Blood Center, New York, New York, USA \\ ${ }^{4}$ Department of Medicine, University of Minnesota School of Medicine, Minneapolis, Minnesota, USA
}

Summary Insulin-dependent diabetes mellitus (IDDM) is associated with autoantibodies to several pancreatic islet antigens. We have described an assay in which autoantibodies displace a radiolabelled monoclonal anti-islet antibody. Sera from $87 \%$ of 429 children at time of diagnosis of IDDM were positive, while sera from control groups had much lower prevalences (1.3-19\%). Sera from $41.9 \%$ of diabetic subjects remained positive after 20 years duration of IDDM. Sera from $23.6 \%$ of parents and $37.9 \%$ of non-diabetic siblings were positive. Twenty relatives who subsequently developed IDDM had the same prevalence of the antibodies ( $85 \%)$ as did the patients at time of diagnosis. These findings confirm that the autoantibodies detected by monoclonal antibody (mAb) 1A2 are common at the onset of IDDM and their presence prior to the onset of hyperglycaemia suggests that this method may be useful in screening non-diabetic populations. The high prevalence of antibodies in relatives reduces the efficacy for diabetes prediction, but suggests either that generation of these antibodies is an autosomal dominant trait, or that the antigen detected by these antibodies is cross-reactive with a common environmental antigen. Differentiation between these hypotheses will await the identification of the specific islet-cell antigen detected by mAb 1A2. [Diabetologia (1996) 39: 1365-1371]

Keywords Islet cell, antigen, autoimmunity, autoantibody.
Insulin-dependent diabetes mellitus (IDDM) is now believed to be an autoimmune disease [1, 2]. Although, at least in animal models, the actual destruction of the pancreatic beta cells is thought to be mediated by a cellular immune process, the presence of autoantibodies against the islet cells is currently the most prevalent indicator and predictor of IDDM [3,

Received: 15 February 1996 and in final revised form: 10 June 1996

Corresponding author: Dr. R. C. McEvoy, Box 1659 Pediatrics, Mount Sinai School of Medicine, New York, N. Y. 100296574, USA

Abbreviations: IDDM, Insulin-dependent diabetes mellitus; mAb 1A2, monoclonal antibody 1A2; GAD, glutamic acid decarboxylase; ICA, islet cell antibody; IAA, insulin autoantibodies; HLA, human leucocyte antigen; MHC, major histocompatibility complex; RIN, rat insulinoma cell line; HIV, human immunodeficiency virus.
4]. Initially, these ICA were detected using immunohistochemical staining of human pancreas by immunoglobulins in human sera [5]. Over the last 20 years, this non-specific localization has been clarified by more sensitive and specific techniques. Antibodies to many islet-cell antigens have been detected, primarily using immunoprecipitation of metabolically labelled human islet proteins by patient sera $[6,7]$. The antigens that have been most extensively characterized are insulin [8], glutamic acid decarboxylase (GAD) [9], carboxypeptidase H [10], and the 69 $\mathrm{kDa}$ antigen related to bovine serum albumin [11]. Several other antigens are currently being characterized and these are still identified by their apparent molecular weights after polyacrylamide gel electrophoresis.

One of these antigens is that detected by monoclonal antibody (mAb) 1A2, a murine monoclonal IgM originally raised against the rat insulinoma cell 
line, RIN 5F. We previously described an assay to detect human antibodies by their ability to displace the radiolabelled $\mathrm{mAb} 1 \mathrm{~A} 2$ from the surface of RIN cells in vitro [12]. Subsequently we have used $\mathrm{mAb} 1 \mathrm{~A} 2$ to detect its antigen in membrane extracts from RIN cells and from rat pancreas and islets [13] and from the pancreas or islets of other mammalian species (dog, pig, Macaque, and human [14]). The antigen is a membrane glycopeptide of molecular weight approximately $155-160 \mathrm{kDa}$ on Western blots of rat pancreas or islets, $118 \mathrm{kDa}$ from RIN cells, and 138 $\mathrm{kDa}$ from human islets [14]. In the rat, the antigen is found only in the pancreas [13]; tissue distribution in humans outside of the pancreas remains unknown. The antibody is directed toward the protein and not the post-translation glycosylation as demonstrated by the immunoprecipitation of the protein by $\mathrm{mAb}$ 1A2 after in vitro translation of pancreatic mRNA [13].

In the present study, we sought to characterize the prevalence of an autoimmune response against this antigen in a larger number of control children, in additional non-diabetic populations, and in firstdegree family members of individuals with IDDM, in order to evaluate the persistence of the immune response after diagnosis of IDDM, and to establish the presence of the antibodies detected by $\mathrm{mAb}$ $1 \mathrm{~A} 2$ prior to the development of glucose intolerance. To clarify the presentation, the ICA detected by displacement of mAb $1 \mathrm{~A} 2$ will be referred to as $138 \mathrm{kDa}$ antibodies after the apparent molecular mass of the human islet antigen detected by $\mathrm{mAb}$ $1 \mathrm{~A} 2$ on Western blots of human pancreatic islet extracts.

\section{Subjects and methods}

Subjects. All blood samples were obtained after approval by the Institutional Review Boards at each of the participating institutions. Each sample obtained for assay was coded and assayed without knowledge of the clinical status. Blood samples were obtained for various diagnostic tests from almost every patient newly diagnosed with IDDM at Mount Sinai Medical Center from 1989 to the present and at Children's Hospital and Medical Center from 1992 to 1995, and any extra serum or plasma was used for the present study. Sera from control patients were obtained from four sources: 1) children seen in the endocrinology clinics at Mount Sinai Medical Center and Children's Hospital Medical Center for any diagnosis other than diabetes were the principal control subjects. Children with a family history of IDDM in a first-degree relative were excluded. Extra serum or plasma after indicated diagnostic tests were completed was used for this study. 2) Serum was also obtained from 150 cord bloods from consecutive deliveries at Mount Sinai Medical Center. Sera from any children born to a diabetic mother to one with serological evidence of exposure to human immunodeficiency virus (HIV) were excluded by the personnel in the blood bank. Cord bloods of 157 sequential deliveries were used with only three samples from HIV-positive patients and four samples from known diabetic pregnancies excluded. 3) Sera were also obtained from 150 consecutive blood donors at Mount Sinai Medical Center. No sera were excluded for either IDDM or HIV-positivity. No demographic information was sought on the actual donors used for this study, but the average age of blood donors in this blood bank averages approximately 28 years. 4) Finally, sera were obtained in the population study from Wadena, Minnesota [15]. A total of 398 sera were analysed for $138 \mathrm{kDa}$ antibodies without knowledge of the metabolic status of the subject, but several of these individuals proved to have abnormal glucose tolerance by the criteria used in that study [15] and/or a family history of diabetes, so only these 242 samples were analysed in this report. Demographic information obtained with informed consent was available for these subjects.

Serum/plasma from additional diabetic patients obtained for other indicated diagnostic tests was also tested for 138 $\mathrm{kDa}$ antibodies in a cross-sectional manner. Sera from many subjects were tested on multiple occasions, but never more often than once per calendar year. No subject's serum was tested more than five times. Since a high percentage of IDDM patients have $138 \mathrm{kDa}$ autoantibodies at time of diagnosis, their presence might be useful in predicting which non-diabetic individuals would be likely to develop IDDM, as are conventional ICA, insulin autoantibodies (IAA), and antibodies to GAD [2]. Therefore, sera were also obtained from first-degree relatives of children with diabetes who were participating in the New York Family Study, a long-term study of the pathogenesis of human diabetes. As part of this study, blood samples were obtained for haemoglobin $A_{l c}$, serum glucose, serum insulin, and IAA, in addition to the $138 \mathrm{kDa}$ antibodies. Most of these subjects were human leucocyte antigen (HLA)-typed by serological methods. Many subjects, including those HLA-identical to the diabetic proband, underwent yearly glucose tolerance testing. Autoantibodies were tested on the samples obtained prior to the infusion of glucose. Some relatives had IDDM, either previously known or diagnosed during the course of these tests. These subjects are included in the diabetic categories so that the analysis of parents and siblings includes only non-diabetic individuals. If the HLA types of both parents were known, the haplotypes of siblings could be determined in almost all cases and haplotype identity between siblings and the diabetic probands in each family ascertained.

As part of the New York Family Study, non-diabetic firstdegree family members have been followed for as long as 17 years with frequent assessments to ascertain the possible risk factors for IDDM. Sera obtained at a time when the glucose tolerance was documented to be normal were available from 20 of the relatives who eventually developed IDDM. These were used for the determination of $138 \mathrm{kDa}$ antibodies.

Assays. All serum or plasma samples were aliquoted for the assay and either stored at $4^{\circ} \mathrm{C}$ and assayed within 1 week or stored frozen at $-20^{\circ} \mathrm{C}$ until later assay.

$138 \mathrm{kD} a$ antibodies. The competitive displacement assay was used as previously published [12], with one modification. The $\mathrm{mAb} 1 \mathrm{~A} 2$ preparation used for iodination was purified from bioreactor tissue culture fluid rather than the ascites preparation used previously. The IgM was purified from the bioreactor supernatant using EZ Sep (Pharmacia, Piscataway N. J., USA). The resulting preparation gave a single pair of bands after polyacrylamide gel electrophoresis under reducing conditions corresponding in apparent molecular mass to those published for murine immunoglobulin $\mu$ heavy chains and $\kappa$ light chains 
indicating isotype identity with that previously described for $\mathrm{mAb} 1 \mathrm{~A} 2$. The specific binding of ${ }^{125}$ I-labelled mAb $1 \mathrm{~A} 2$ to RIN cells in vitro was $27 \%$. Based on radioactive counts, the intra-assay variation between replicate samples was $8 \%$ and the interassay variation was $15 \%$. The displacement value designated as "positive" in the assay was determined in two ways. First, the data from sera of the control children were analysed. These were not normally distributed; therefore, the individual values were ranked in order of increasing displacement. Goodness-of-fit testing was performed as the higher samples were deleted until the distribution of the data normalized. The highest displacement of the 1583 samples remaining with a normal distribution was $27.0 \%$. This, as expected, was almost identical to the second method, the mean of these normally distributed values $\pm 3 \mathrm{SD}$, or $26.8 \%$. Therefore, any sample with a displacement greater than $27.0 \%$ was designated as positive. Those with displacement less than or equal to $27 \%$ were negative. This is similar to the "normal" range determined in our original report based on the first 333 control subjects, less than or equal to $24 \%$ [12].

Each sample was assayed blindly, but any negative sample from an individual known to have IDDM was verified in a second assay and, conversely, any positive result from an individual identified as non-diabetic was also verified by repeat assay. All of these equivocal samples had calculated displacement values within $5 \%$ of the $27.0 \%$ cut-off between positive and negative and therefore were greater than 2 SD from the control mean. The original designation as positive or negative was verified by the second assay for all but 33 specimens of the more than $5600(0.6 \%)$ reported here. These few samples giving an opposite result on the second assay were assayed a third time and finally designed as indicated by two of the three assays.

$I A A$. The liquid phase, competitive displacement assay was used identically as previously described [16]. ${ }^{125}$ I-labelled insulin (specific activity, $2000 \mathrm{Ci} / \mathrm{mmol}$ ) was obtained from Amersham (Chicago, Illinois, USA). Positive was equal to or greater than $34 \mathrm{nU} / \mathrm{ml}$. Our laboratory has participated in the International Diabetes Workshop for insulin antibody assays and was found to be $100 \%$ specific and $100 \%$ sensitive in this assay.

HLA Typing. The HLA A, B, C, and DR types on newly diagnosed patients and family members were determined from peripheral blood mononuclear cells by serological methods. The HLA A, B, and C types were ascertained by the contrast fluorescence test [17]. The HLA DR typing was performed using the two-colour fluorescence test [18]. These are both modifications of the microcytotoxicity assay. Subject samples were standardized against over 180 monospecific and oligospecific reagents standardized by the latest International Histocompatibility Workshop at the time of the assay.

\section{Statistical analysis}

A microcomputer statistical package (Microstat II, Ecosoft, Indianapolis, Ind., USA) was used for all analyses. After goodness-of-fit testing revealed that many of the data sets to be evaluated did not have a normal distribution, analysis of variance was employed to ascertain the significance of any differences. The differences in the percentage positive for the autoantibody detected by mAb $1 \mathrm{~A} 2$ in each of the populations tested were determined by chi-square. Differences were significant for $<0.05$.

\section{Results}

Newly diagnosed IDDM patients and control children. Among 429 children with IDDM, 373 (86.9\%) had $138 \mathrm{kDa}$ autoantibodies whereas only 73 of 1656 control children were positive $(4.4 \%$, significantly different, $\left.p=4.7 \times 10^{-16}\right)$. The proportion of control children with autoantibodies increased slightly from $3.0 \%$ in our previous report [12] to $4.4 \%$ in the much larger number of children reported here and the percentage of IDDM patients who were positive for these antibodies decreased from 93.7 to $86.9 \%$. However, the mean level of displacement of $\mathrm{mAb}$ $1 \mathrm{~A} 2$ over time has remained remarkably constant in both the control $(4.1 \pm 6.6$ previously vs $5.2 \pm 7.2 \%$ in this study) and the IDDM groups (76.2 \pm 30.1 previously vs $75.9 \pm 36.1 \%$ in this study). There was no significant difference in the mean age of the children with IDDM (10.6 \pm 2.1 years) compared with the control children $(9.8 \pm 2.9$ years $)$.

There was no difference in the incidence of the 138 $\mathrm{kDa}$ autoantibodies in the childhood control population based on sex: males, $n=792,30$ positive $=3.8 \%$ and females, $n=864,43$ positive $=5.0 \%, p=0.29$. Similarly, the incidence of $138 \mathrm{kDa}$ antibodies in the IDDM patients also did not differ between the sexes: males, $n=221,190$ positive $=86.0 \%$ and females, $n=208,183$ positive, $88.0 \%, p=0.636$. As in our previous report, there was no association between age at onset and the prevalence of the $138 \mathrm{kDa}$ autoantibodies in the larger group presented here, either expressed as percentage of displacement compared with age $(r=0.16, p=0.72)$ or as percentage positive for the autoantibodies. As others [19] and we [16] have previously reported, a linear negative correlation between age at onset and the presence of IAA at diagnosis can be demonstrated. The rate of IAA in the patients reported here fell from 22 in the 28 patients diagnosed at less than 2 years of age $(78.6 \%)$ to 2 in the 49 patients diagnosed at greater than 16 years of age $\left(4.0 \%, p=2.199 \times 10^{-8}\right)$.

Although an early report found an association between HLA B8 and ICA [20], subsequent studies have demonstrated no variation in the incidence of conventional ICA, detected by indirect immunofluorescence at diagnosis and any HLA type. Antibodies to GAD have been positively correlated with class II MHC antigens, specifically DQ2 which is closely associated with DR3 [21]. HLA DR typing was available on 289 of the newly diagnosed patients presented here $(67 \%$, Table 1$)$. The prevalence of 138 $\mathrm{kDa}$ autoantibodies in this subgroup was not different from the total population. There were no differences in the expression of any of the Class I MHC antigens and the incidence of $138 \mathrm{kDa}$ autoantibodies at diagnosis of IDDM (Data not shown). As expected, most of the patients with IDDM expressed either HLA DR3 or DR4 or both (239 of $289,82.7 \%)$. 
Table 1. Relationship of autoantibodies detected by mAb $1 \mathrm{~A} 2$ and HLA DR type in patients at time of IDDM diagnosis

\begin{tabular}{lrll}
\hline Group & Number & $\begin{array}{l}\text { Number } \\
\text { positive }\end{array}$ & $\begin{array}{l}\text { Percent } \\
\text { positive }^{\mathrm{a}}\end{array}$ \\
\hline All & 289 & 259 & 89.6 \\
Non 3/Non 4 & 50 & 43 & 86.0 \\
3/Non 4 & 65 & 61 & 93.8 \\
4/Non 3 & 105 & 92 & 87.6 \\
3/4 & 69 & 63 & 91.3 \\
\hline
\end{tabular}

${ }^{a}$ No values significantly different from all IDDM patients $p>0.1$

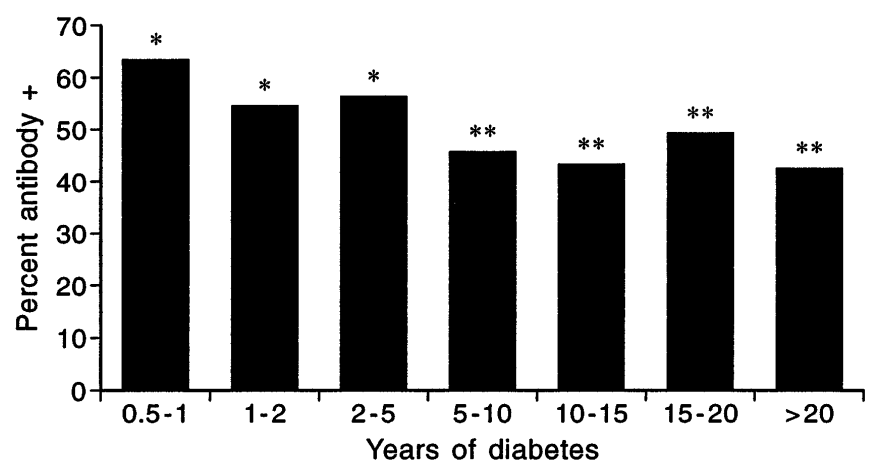

Fig. 1. The persistence of positivity for antibodies to the 138 $\mathrm{kDa}$ antigen after diagnosis of IDDM is illustrated. Sera from the majority of subjects were antibody-positive until after 5 years' duration of diabetes and even after 20 years, sera from over $40 \%$ of subjects were positive. $n=137$ (0.5-1 years), 222 (1-2 years), 471 ( $2-5$ years), 628 (5-10 years), 255 (1015 years), 110 (15-20 years) and 43 (>20 years). * Significantly less than newly diagnosed subjects, $p<0.0001$. ** Significantly less than $0.5-1$ year, $p<0.03$

There were no differences in incidence of the 138 $\mathrm{kDaDa}$ autoantibodies in the children expressing the MHC Class II antigens associated with IDDM (HLA DR3 and DR4) and those expressing other Class II serotypes. Since these children were participants in a family study, haplotypes could be predicted for most of the IDDM patients. Although the numbers of subjects in these subgroups were small, there was also no detectable positive or negative association between any haplotype and the production of the $138 \mathrm{kDa}$ autoantibodies.

Other control populations. The control population obtained from the endocrinology clinic by necessity included many children with autoimmune diseases. To ascertain whether these control subjects were reflective of more normal populations, we obtained coded sera from cord bloods and only 2 of the 150 samples tested $(1.3 \%)$ met the criteria for positivity in the $138 \mathrm{kDaDa}$ autoantibody assay. This was not significantly different from the control children $(p=0.07)$. Twelve of the 150 sera from blood donors were positive for $138 \mathrm{kDa}$ antibodies, $8.0 \%$, an incidence which again was not significantly different from the control children $(p=0.074)$. We also obtained coded specimens from the diabetes study in Wadena [15]. Of 242 specimens analysed (age $50 \pm 15$ years), $17.7 \%$ were positive, very significantly different from the control children $\left(p=7.57 \times 10^{-11}\right)$. Although the numbers in the other groups of control subjects were smaller, the incidence of autoantibody positivity was also greater in the older subjects than in both the cord bloods $(p=4.4 \times$ $\left.10^{-7}\right)$ and the blood donors $(p=0.0068)$. There was no difference in the older adults between the 119 males ( 23 positive, $19.3 \%$ ) and the 123 females (20 positive, $16.0 \%, p=0.495)$. Further breakdown of the older subjects by age (20-39 years $n=94,40-59$ years $n=96$, and greater than 60 years $n=52$ ) revealed no significant differences $(18.9,13.5$, and $23.0 \%$ respectively) as the relatively small number of subjects in these subgroups did not permit the apparent decrease in prevalence of autoantibodies in the 40-59-year-old group to reach statistical significance $(p>0.32)$.

Persistence of $138 \mathrm{kDa}$ autoantibodies after diagnosis (Fig. 1). ICA have been shown to rapidly diminish in prevalence over time after diagnosis; thus only a few IDDM patients have detectable ICA after 2 years of diabetes [22]. In contrast, antibodies to GAD seem to persist in the majority of subjects for years after diagnosis [23-24]. We tested over 1800 sera from IDDM patients in a cross-sectional manner for 138 $\mathrm{kDa}$ autoantibodies. The prevalence of $138 \mathrm{kDa}$ antibodies fell significantly over the first year of IDDM from $86.9 \%$ at diagnosis to $62.8 \%\left(p=3.91 \times 10^{-11}\right)$. The prevalence of the antibodies remained relatively constant thereafter and only reached a significantly lower rate after 5 years of diabetes $(45.4 \%$ $\left.p=2.24 \times 10^{-4}\right)$. However, even after 20 years of IDDM, over $40 \%$ of patients remained positive for $138 \mathrm{kDa}$ autoantibodies, significantly greater than any of the control groups $\left(p<3.60 \times 10^{-4}\right.$, vs Wadena control subjects).

$138 \mathrm{kDa}$ Autoantibodies in first-degree relatives of patients with IDDM. We also examined the expression of $138 \mathrm{kDa}$ autoantibodies in siblings and parents of children with IDDM. Of over 400 parents whose sera were tested, $23.6 \%$ proved to be positive by the criteria defined by the childhood control subjects. In these subjects, sera from mothers were more likely to be positive than sera from fathers ( 33.3 vs $17.9 \%$, $\left.p=3.16 \times 10^{-4}\right)$. Sera from almost 500 siblings were also tested. Again, there was a high prevalence of $138 \mathrm{kDa}$ autoantibodies with almost $38 \%$ of the siblings positive for this autoantibody. There was no difference between the sisters and brothers in the rate of $138 \mathrm{kDa}$ antibody positivity (Table 2). The 138 $\mathrm{kDa}$ antibody status of both parents was known for 302 of the 494 siblings and $36.8 \%$ of these were positive for $138 \mathrm{kDa}$ antibody, not significantly different 
Table 2. Prevalence of autoantibodies detected by mAb $1 \mathrm{~A} 2$ in siblings of children with IDDM

\begin{tabular}{lccc}
\hline Siblings $^{\mathrm{a}}$ & Number & $\begin{array}{l}\text { Number } \\
\text { Positive }\end{array}$ & \% Positive \\
\hline All & 494 & 187 & $37.9^{\mathrm{b}}$ \\
$\quad$ Brothers & 252 & 96 & $38.1^{\mathrm{b}}$ \\
$\quad$ Sisters & 242 & 91 & $37.6^{\mathrm{b}}$ \\
Parents' antibody & 192 & 76 & $39.6^{\mathrm{c}}$ \\
$\quad$ status unknown & & & \\
Parents both negative & 129 & 8 & $6.2^{\mathrm{d}}$ \\
One parent positive & 114 & 57 & $50.0^{\mathrm{e}}$ \\
Both parents positive & 59 & 46 & $78.0^{\mathrm{f}}$ \\
\hline
\end{tabular}

a Ages: brothers, $12.8 \pm 4.7$ years, sisters, $11.9 \pm 3.9$ years

${ }^{\mathrm{b}}$ Different from control children, $p<0.0001$

${ }^{\mathrm{c}}$ Not significantly different from all, $p=0.68$

${ }^{\mathrm{d}}$ Significantly different from all, $p=8.08 \times 10^{-11}$; not significantly different from control children, $p=0.21$

e Significantly different from all, $p=0.017$

${ }^{\mathrm{f}}$ Significantly different from all, $p=3.76 \times 10^{-9}$

Table 3. Relationship between positivity for autoantibodies detected by mAb 1A2, HLA DR types, and identity to proband

\begin{tabular}{lcll}
\hline Group & Number & $\begin{array}{l}\text { Number } \\
\text { positive }\end{array}$ & $\begin{array}{l}\text { Percent } \\
\text { positive }\end{array}$ \\
\hline DR types all & 214 & 72 & 33.6 \\
$\quad$ Non 3/Non 4 & 57 & 19 & $33.3^{\mathrm{a}}$ \\
3/Non 4 & 53 & 17 & $32.1^{\mathrm{a}}$ \\
4/Non 3 & 70 & 21 & $30.0^{\mathrm{a}}$ \\
3/4 & 34 & 15 & $44.1^{\mathrm{a}}$ \\
Relation to & & & \\
proband & & & \\
$\quad$ Non-identical & $62^{\mathrm{b}}$ & 19 & $30.6^{\mathrm{a}}$ \\
$\quad$ Haplo-identical & $81^{\mathrm{b}}$ & 26 & $32.1^{\mathrm{a}}$ \\
$\quad$ Identical & $71^{\mathrm{b}}$ & 27 & $38.0^{\mathrm{a}}$ \\
\hline
\end{tabular}

${ }^{a}$ Not significantly different from all, $p>0.05$

${ }^{\mathrm{b}}$ Not significantly different from expected distribution of $25 \%, 50 \%$, and $25 \%, p>0.05$

from the entire group. When these siblings were subdivided depending on the positivity of their parents, three subgroups could be differentiated. If both of the parents were $138 \mathrm{kDa}$ antibody-negative, the rate of positivity among the siblings was $6.2 \%$, not significantly different from that in the control children $(p=0.21)$ and significantly below that of the total sibling group $\left(p=8.08 \times 10^{-11}\right)$. If only one parent was positive, the prevalence in the siblings increased to $50 \%$, significantly above that of the total sibling group $(p=0.017)$. Finally, if both parents were 138 $\mathrm{kDa}$ antibody positive, the prevalence of $138 \mathrm{kDa}$ antibodies in the siblings was still greater $(78.0 \%)$, significantly greater than that of the total group $\left(p=3.76 \times 10^{-9}\right)$ and also greater than those siblings with only one parent positive in the assay $\left(p=3.8 \times 10^{-4}\right)$.

HLA typing was available on just over half of these siblings. The incidence of $138 \mathrm{kDa}$ autoantibodies in the siblings whose HLA types were known, $33.6 \%$ (Table 3 ), did not differ from that of the entire group of siblings (Table 2). There were no significant differences in the incidence of $138 \mathrm{kDa}$ antibodies among the siblings based on Class I major histocompatibility complex (MHC) antigen expression (data not shown). The Class II DR antigens were also not associated with any difference in the incidence of $138 \mathrm{kDa}$ autoantibodies, even in the minority of siblings who did not express DR3 or DR4, the alleles associated with increased susceptibility to IDDM. The diabetic proband and parents of these 214 siblings had also been typed and therefore HLA haplotypes could be ascertained and compared to that of the proband. Although the incidence of $138 \mathrm{kDa}$ antibodies in the siblings who were HLAidentical to their sibling with IDDM was slightly greater than those who were non-identical (38.0 positive vs $30.6 \%$ ), this small difference did not reach statistical significance $(p=0.23)$.

138 kDa autoantibodies present prior to diagnosis. Serum samples taken at a time when metabolic normality had been documented were available on 20 relatives who subsequently presented with IDDM. Seventeen of these subjects $(85 \%)$ were positive for 138 $\mathrm{kDa}$ antibodies on the samples obtained 1 month to 14 years (average 4.6 years, median 3.2 years) prior to the diagnosis of IDDM. Two of the three patients who were negative for $138 \mathrm{kDa}$ antibodies were positive for IAA, for a $95 \%$ ascertainment using both autoantibodies.

\section{Discussion}

Autoantibodies have been proven to help in the accurate prediction of the development of IDDM in nondiabetic individuals (discussed at length in [25]), especially since many of them, now including $138 \mathrm{kDa}$ autoantibodies, have been demonstrated to be present prior to the onset of hyperglycaemia. Using the conventional definitions [26], the $138 \mathrm{kDa}$ antibody is comparable to the other autoantibodies currently in use to predict IDDM: sensitivity, $86.9 \%$; specificity, $95.6 \%$; positive predictive value, $95.2 \%$; and negative predictive value, $87.9 \%$. The presence of the $138 \mathrm{kDa}$ autoantibodies in non-diabetic subjects who eventually develop IDDM with a comparable incidence to that present at diagnosis also supports the utility of this test in screening for IDDM.

Other studies measuring multiple autoantibodies have established that sensitivity can approach $100 \%$ by measuring three different autoantibodies, that is, close to $100 \%$ of individuals with IDDM will be positive for at least one of three autoantibodies [27]. The principal issue to be addressed now is the relative costs of the different assays. In this regard, the 138 
$\mathrm{kDa}$ assay, being essentially a solid-phase competitive binding assay, competes very favourably. One technician can easily assay 500 patient samples per week, including confirmation of all positives in a second assay. The benchmark immunofluorescence ICA assay is very labour-intensive and relies on a subjective assessment of positivity. The most recent assays for GAD are approaching the ease of the $138 \mathrm{kDa}$ assay, although some still rely on an electrophoresis step after immunoprecipitation, which adds time and cost. The liquid-phase IAA assay is currently the easiest and least expensive of the pancreatic autoantibody assays. Now that we have purified the $138 \mathrm{kDa}$ antigen, we plan to develop a liquid phase assay for the $138 \mathrm{kDa}$ antibodies as well.

The determinations of sensitivity and specificity used above were based on the data from the childhood control subjects. Certainly, as the control population ages the background false-negative rate increases, thus reducing specificity and positive predictive value to unacceptably low levels. This is also true in the data from first-degree family members in which about one-quarter of parents and one-third of siblings were positive. Thus, the addition of 138 $\mathrm{kDa}$ antibody testing in screening first-degree family members would yield only a slight increase in sensitivity at the expense of a marked decrease in specificity. Using highly sensitive assays for thyroid autoantibodies in families, it has been suggested that the ability to produce these self-reactive humoral immune responses is an autosomal dominant trait [28]. In that study, approximately one-third of family members were positive for antibodies to thyroid peroxidase or thyroglobulin. Our data on $138 \mathrm{kDa}$ autoantibodies in first-degree family members would support the same hypothesis. The siblings whose parents were both negative in the assay had no increase in the incidence of positivity. The $50 \%$ positivity with one parent who was positive and $78 \%$ positivity when both parents were positive are almost exactly what would be predicted by an autosomal dominant inheritance. We were unable to demonstrate any linkages between the generation of these autoantibodies and expression of HLA antigens or of HLA identity to the proband with IDDM. The production of anti-thyroid antibodies was also not linked to HLA [28]. The autosomal dominance of anti-thyroid antibodies could only be demonstrated in females presumably due to a markedly decreased penetrance in males. We were unable to demonstrate any differences in the generation of $138 \mathrm{kDa}$ autoantibodies between males and females, except in the mothers of IDDM patients, who showed a significantly higher incidence of positivity, but no higher than that of the siblings (Table 2). Since siblings did not differ in incidence of $138 \mathrm{kDa}$ autoantibodies by sex, the low rate of antibodies in the fathers remains to be explained.
Autoimmune diseases tend to increase in prevalence with increasing age so the increase in $138 \mathrm{kDa}$ autoantibodies with age is not novel. However, the data on the older control subjects, particularly the increase in incidence of antibodies in the older completely characterized population from the Wadena study [15], suggest another possible explanation for the high rates of $138 \mathrm{kDa}$ antibodies in the first-degree family members. This increase may be attributed to an antibody response to an environment antigen the older the subject, the more likely was exposure to have occurred. This was not the case for $138 \mathrm{kDa}$ antibodies at diagnosis nor anti-thyroid antibodies among the families with thyroid disease [28], although the age range at time of diagnosis in the present study is limited to individuals under age 20 years, and the number of subjects in the latter study was insufficient to detect any but a strong correlation. These data still support the association of the 138 $\mathrm{kDa}$ antibodies with IDDM.

The high incidence of positivity in the first-degree family members can also be explained by the environmental trigger hypothesis. The presence of antibodies in the parents would indicate exposure to the environmental antigen; the children whose parents are exposed would be more likely to be exposed themselves and therefore be more likely to have mounted an autoimmune response. As one example, in the non-obese diabetic mouse, T-cell cross-reactivity could be demonstrated between GAD and coxsackie virus [29]. The differentiation between these two hypotheses must await the specific identification of the epitope detected by mAb $1 \mathrm{~A} 2$ and, by inference, the autoreactive antibodies in human sera.

One of the characteristics of the antibodies detected by ICA was that they usually disappeared over the first few years of IDDM. This was believed to reflect removal of the antigen by the autoimmune process [20]. More recently, antibodies to GAD [23, 24] have been found to persist for extended periods after the diagnosis of IDDM as was the case for $138 \mathrm{kDa}$ antibody (Fig.1). Since antibodies to GAD are a significant contributor to ICA, the loss of ICA positivity, but not anti-GAD antibodies, suggests that the ICA assay is less sensitive to low titres of antibody than the other, more quantitative assays.

In summary, we have confirmed the close association between autoantibodies to $138 \mathrm{kDa}$ and IDDM, especially in younger individuals without relatives with diabetes. The rise in the prevalence of the antibodies with increasing age and the high incidence in first-degree family members decreases the utility of the antibody screening in these populations. However, these antibodies could significantly increase the sensitivity of screening programmes involving children in families without diabetes. 
Acknowledgements. The authors wish to thank Ms. D. Hsu and Ms. G. Ngai for their skillful technical assistance. These studies were supported by funding from the National Institutes of Health (DK-19631, DK-33225, DK-43675), the Robert Wood Johnson Jr. Charitable Trust, the Carole and Michael Friedman and Family Young People's Diabetes Unit, the Juvenile Diabetes Foundation International, the American Diabetes Association - New York Downstate Affiliate, the National Foundation for Diabetes, and the Eising/Benaroya Diabetes Research Endowment.

\section{References}

1. Bach J-F (1994) Insulin-dependent diabetes mellitus as an autoimmune disease. Endocr Rev 15: 516-542

2. Atkinson MA, MacLaren NK (1994) The pathogenesis of insulin-dependent diabetes mellitus. New Engl J Med 331: 1428-1435

3. Bruining JG, Molenaar JL, Grobbee DE et al. (1989) Ten year follow-up study of islet cell antibodies and childhood diabetes mellitus. Lancet 1: 1100-1103

4. Riley WJ, MacLaren NK, Krischer J et al. (1990) A prospective study of the development of diabetes in relatives of patients with insulin-dependent diabetes. New Engl J Med 323: 1167-1172

5. Bottazzo GF, Florin-Christensen A, Doniach D (1974) Islet cell antibodies in diabetes mellitus with autoimmune polyendocrine deficiencies. Lancet II: 1279-1283

6. Atkinson MA, MacLaren NK (1993) Islet cell autoantigens in IDDM. Diab Rev 1: 191-203

7. Bosi E, Bonifacio E, Bottazzo GF (1993) Autoantigens in IDDM.Diab Rev 1: 204-214

8. Palmer JP, Asplin CM, Clemons P et al. (1983) Insulin antibodies in insulin-dependent diabetes before insulin treatment. Science 222: 1337-1339

9. Baekkeskov S, Nielsen JH, Marner B, Bilde T, Ludvigsson J, Lernmark A (1982) Autoantibodies in newly diagnosed diabetic children immunoprecipitate human pancreatic islet cell proteins.Nature 298: 167-169

10. Castano L, Russo E, Zhou L, Lipes MA, Eisenbarth GS (1991) Identification and cloning of a granule autoantigen (carboxypeptidase $\mathrm{H}$ ) associated with type I diabetes. J Clin Endocrinol Metab 73: 1197-1201

11. Pietropaolo M, Castano L, Babu S et al. (1993) Islet cell autoantigen $69 \mathrm{kD}$ (ICA 69) Molecular cloning and characterization of a novel, diabetes-associated autoantigen. J Clin Invest 92: 359-371

12. Thomas NM, Ginsberg-Fellner F, McEvoy RC (1990) Strong association between diabetes and displacement of mouse anti-rat insulinoma cell monoclonal antibody by human sera in vitro. Diabetes 39: 1203-1211

13. Kohtz JD, Thomas NM, Ginsberg-Fellner F, McEvoy RC 1990) A novel beta cell plasma membrane antigen associated with anti-pancreatic autoimmunity in insulin-dependent diabetes mellitus. Diabetes 41:[Suppl 1] 122A (Abstract)

14. Felix I, Vargas-Rodriguez I, Pan Y-X, Thomas NM, McEvoy RC (1992) Identification of rat islet cell surface antigens by monoclonal antibodies, PAGE, and Western blotting.Anat Rec 232: 32A-33A (Abstract)

15. French LR, Boen JR, Martinez AM, Bushhouse SA, Sprafka JM, Goetz FC (1990) Population-based study of impaired glucose tolerance and type II diabetes in Wadena, Minnesota. Diabetes 39: 1131-1137

16. McEvoy RC, Witt ME, Ginsberg-Fellner F, Rubinstein P (1986) Anti-insulin antibodies in children with type I diabetes mellitus. Genetic regulation of production and presence at diagnosis before insulin replacement. Diabetes 35: 634641

17. Martel JL, Jaramillo S, Allen FH Jr, Rubinstein P (1974) Serology for automated cytotoxicity assays: contrast fluorescence test. Vox Sang 27: 13-20

18. Van Rood JJ, Van Leeuven A, Ploehm SS (1976) Simultaneous detection of two cell populations by two color fluorescence and application to the recognition of B-cell determinants. Nature 262: 795-797

19. Arslanian SA, Becker DJ, Rabin B et al. (1985) Correlates of insulin antibodies in newly-diagnosed children with insulin-dependent diabetes before insulin therapy. Diabetes 34: 926-930

20. Morris PJ, Vaugh H, Irvine WJ et al. (1976) HLA and pancreatic islet cell antibodies in diabetes. Lancet 2: 652-654

21. Serjeantson SW, Court J, Mackay IR et al. (1993) HLA-DQ genotypes are associated with autoimmunity to glutamic acid decarboxylase in insulin-dependent diabetes patients. Human Immunol 38: 97-104

22. Gleichmann H, Bottazzo GF (1990) The humoral anti-islet immune response: cytoplasmic islet-cell antibodies: technical aspects and clinical applications. In: Ginsberg-Fellner F, McEvoy RC (eds) Autoimmunity and the pathogenesis of diabetes. Springer-Verlag, New York, pp 68-86

23. Christie MR, Daneman D, Champagne P, Delovitch TL (1990) Persistence of serum antibodies to $64,000-\mathrm{M}_{\mathrm{r}}$ islet cell protein after onset of type 1 diabetes. Diabetes 39: 653-656

24. Sundkvist G, Hagopian WA, Landin-Olsson M, Lernmark Å, Ohlsson L, Ericsson C, Ahlmén J (1994) Islet cell antibodies, but not glutamic acid decarboxylase antibodies, are decreased by plasmapheresis in patients with newly diagnosed insulin-dependent diabetes mellitus. J Clin Endocrinol Metab 78: 1159-1165

25. Palmer JP (1996) Prediction, prevention, and genetic counseling in IDDM. John Wiley and sons, Chicester

26. Ingelfinger JA, Mosteller F, Thibodeau LA, Ware JH (1994) Biostatistics in clinical medicine, 3rd ed, McGrawHill New York

27. Hagopian WA, Sanjeevi CB, Kockum I et al. (1995) Glutamate decarboxylase-, insulin-, and islet cell-antibodies and HLA typing to detect diabetes in a general populationbased study of Swedish children. J Clin Inv 95: 1505-1511

28. Phillips D, McLachlan S, Stephenson A et al. (1990) Autosomal dominant transmission of autoantibodies to thyroglobulin and thyroid peroxidase. J Clin Endocrinol Metab 70: 742-746

29. Tian J, Lehmann PV, Kaufman DL (1994) T cell cross-reactivity between coxsackievirus and glutamate decarboxylase is associated with a murine diabetes susceptibility allele. J Exp Med 180: 1979-1984 